\title{
Are Bacterial Volatile Compounds Poisonous Odors to a Fungal Pathogen Botrytis cinerea, Alarm Signals to Arabidopsis Seedlings for Eliciting Induced Resistance, or Both?
}

\author{
Rouhallah Sharifi ${ }^{1,2}$ and Choong-Min Ryu ${ }^{1,3 *}$ \\ ${ }^{1}$ Molecular Phytobacteriology Laboratory, Super-Bacteria Research Center, Korea Research Institute of Bioscience and \\ Biotechnology, Daejeon, South Korea, ${ }^{2}$ Department of Plant Protection, College of Agriculture and Natural Resources, Razi \\ University, Kermanshah, Iran, ${ }^{3}$ Biosystems and Bioengineering Program, University of Science and Technology, Daejeon, \\ South Korea
}

\section{OPEN ACCESS}

Edited by:

Brigitte Mauch-Mani,

Université de Neuchâtel, Switzerland

Reviewed by:

Aurélien Bailly,

University of Zurich, Switzerland Anton Hartmann, Helmholtz Zentrum München-German Research Center for Environmental Health, Germany

*Correspondence: Choong-Min Ryu cmryu@kribb.re.kr

Specialty section: This article was submitted to Plant Biotic Interactions, a section of the journa Frontiers in Microbiology

Received: 01 September 2015 Accepted: 05 February 2016 Published: 23 February 2016

Citation:

Sharifi R and Ryu C-M (2016) Are Bacterial Volatile Compounds

Poisonous Odors to a Fungal Pathogen Botrytis cinerea, Alarm Signals to Arabidopsis Seedlings for Eliciting Induced Resistance, or

Both? Front. Microbiol. 7:196. doi: 10.3389/fmicb.2016.00196
Biological control (biocontrol) agents act on plants via numerous mechanisms, and can be used to protect plants from pathogens. Biocontrol agents can act directly as pathogen antagonists or competitors or indirectly to promote plant induced systemic resistance (ISR). Whether a biocontrol agent acts directly or indirectly depends on the specific strain and the pathosystem type. We reported previously that bacterial volatile organic compounds (VOCs) are determinants for eliciting plant ISR. Emerging data suggest that bacterial VOCs also can directly inhibit fungal and plant growth. The aim of the current study was to differentiate direct and indirect mechanisms of bacterial VOC effects against Botrytis cinerea infection of Arabidopsis. Volatile emissions from Bacillus subtilis GB03 successfully protected Arabidopsis seedlings against B. cinerea. First, we investigated the direct effects of bacterial VOCs on symptom development and different phenological stages of $B$. cinerea including spore germination, mycelial attachment to the leaf surface, mycelial growth, and sporulation in vitro and in planta. Volatile emissions inhibited hyphal growth in a dose-dependent manner in vitro, and interfered with fungal attachment on the hydrophobic leaf surface. Second, the optimized bacterial concentration that did not directly inhibit fungal growth successfully protected Arabidopsis from fungal infection, which indicates that bacterial VOC-elicited plant ISR has a more important role in biocontrol than direct inhibition of fungal growth on Arabidopsis. We performed qRT-PCR to investigate the priming of the defense-related genes PR1, PDF1.2, and ChiB at 0, 12, 24, and $36 \mathrm{~h}$ post-infection and 14 days after the start of plant exposure to bacterial VOCs. The results indicate that bacterial VOCs potentiate expression of PR1 and PDF1.2 but not ChiB, which stimulates SA- and JA-dependent signaling pathways in plant ISR and protects plants against pathogen colonization. This study provides new evidence for bacterial VOC-elicited plant ISR that protects Arabidopsis plants from infection by the necrotrophic fungus $B$. cinerea. Our work reveals that bacterial VOCs primarily act via an indirect mechanism to elicit plant ISR, and have a major role in biocontrol against fungal pathogens.

Keywords: bacterial volatile organic compounds, phytohormones, induced systemic resistance, plant growthpromoting rhizobacteria, biofilm formation, leaf surface attachment 


\section{INTRODUCTION}

Plants have evolved complex and efficient surveillance systems that respond to abiotic and biotic stresses, including pests and pathogens (Agrios, 2004). Small signaling molecules elicit plant cell defense responses throughout the plant; these include the phytohormones salicylic acid (SA), jasmonic acid (JA), and ethylene (ET) (Pieterse et al., 2009). Each hormone has a particular function in eliciting plant immunity. For example, SA-dependent signaling is triggered by necrotizing avirulent pathogens, whereas JA signaling is triggered by necrotrophic pathogens and insect pests (Mysore and Ryu, 2004). Plants with activated immune systems produce diverse classes of pathogenesis-related (PR) proteins and toxic phenol compounds such as phytoalexins, which can function to induce subsequent defense mechanisms (Ryals et al., 1996; Pieterse et al., 2009; Balmer et al., 2013). Plant immune responses can be induced by pathogens, insects, and beneficial root-associated bacteria designated as plant growth-promoting rhizobacteria/fungi (PGPR/PGPF). PGPR/PGPF systems elicit similar plant immune responses as those elicited by pathogens and insects (Kloepper et al., 2004). Plant resistance to pathogens and insects is largely mediated by the two plant hormones, JA and ET, which elicit induced systemic resistance (ISR) responses (Pieterse et al., 2009; Balmer et al., 2013). Previous studies reported that ISR were effectively elicited by necrotrophic pathogens such as Pectobacterium carotovorum (Han et al., 2006; Farag et al., 2013). To identify microbial determinants that elicit ISR, microbial secreted products have been tested on plants under greenhouse and field conditions, including siderophores, phytohormone mimetics, $\mathrm{N}$-acyl homoserine lactone, vitamins, and cell wall components such as chitin, glucan, and lipopolysaccharides (Lyon, 2007; Hartmann and Schikora, 2012; Kanchiswamy et al., 2015a,b; Lee et al., 2015).

New investigations clearly demonstrate that PGPR/PGPF emit volatile compounds that trigger robust plant systemic defense responses against pathogenic bacteria (Ryu et al., 2004; Kishimoto et al., 2007; Rudrappa et al., 2010; Song and Ryu, 2013). Ryu et al. (2004) and Rudrappa et al. (2010) shown that bacterial volatile organic compounds (VOCs) activate plant defenses in a strain-specific manner. Ryu et al. (2004) reported that activation of systemic defense in Arabidopsis against Erwinia carotovora subsp. carotovora elicited by Bacillus subtilis strain GB03 VOCs depends on ET pathways but was independent of JA and SA pathways. Rudrappa et al. (2010) showed that $\mathrm{SA}$ and $\mathrm{ET}$ are required for $B$. subtilis FB17 VOC-elicited ISR in Arabidopsis against the hemibiotrophic pathogen Pseudomonas syringae pv. tomato DC3000, whereas JA was not required. Not only bacteria strains but also a single volatiles can employ different signaling pathways to boost plant defense. Some bacteria emit 2,3-butanediol and its precursor acetoin as VOCs; these volatiles have roles in plant protection against pathogens (Farag et al., 2006). 2,3-butanediol activated PR-4 expression and SA-dependent signaling in Agrostis stolonifera (Cortes-Barco et al., 2010a), application of $100 \mu \mathrm{M}$ 2,3-butanediol on Nicotiana benthamiana seedlings elicited resistance against the hemibiotrophic fungus Colletotrichum orbiculare (Cortes-Barco et al., 2010b) by increasing basic PR proteins expression, which are markers of JA-dependent signaling, whereas there was no change in acidic PR proteins expression, which are markers of SA-dependent signaling. 2,3-butanediol activated both SA- and JA-dependent signaling pathways in Arabidopsis thaliana in response to abiotic stress (Cho et al., 2008). Currently, there is debate in the literature regarding the function and activity of Bacillus VOCs.

Many studies report antagonistic effects of VOCs on plant pathogenic fungi (McCain, 1966; Kai et al., 2007). VOCs can act as antibiotics and directly inhibit mycelial growth and spore germination of pathogenic fungi (Kai et al., 2007; Vespermann et al., 2007). Fiddaman and Rossall (1993) and Chaurasia et al. (2005) show that B. subtilis VOCs deform mycelia and inhibit growth of some pathogenic and biocontrol fungi. B. subtilis VOCs induce protoplasm retraction in Botrytis cinerea hyphae (Chen et al., 2008). However, most of these reports utilize a dual culture method that exposes pathogenic fungi to extremely high VOC levels, which do not occur under natural conditions. Therefore, it is necessary to determine whether Bacillus VOCs protect Arabidopsis against $B$. cinerea via ISR or by inhibiting fungal growth or infection.

The objective of this work was to investigate direct and indirect mechanisms of Arabidopsis protection conferred by $B$. subtilis strain GB03 VOCs against the necrotrophic fungal pathogen $B$. cinerea. First, we evaluated the effects of different VOC concentrations on stages of the B. cinerea life cycle and during Arabidopsis infection. Secondly, we examined direct and indirect VOC effects on Arabidopsis protection against pathogenic fungal infection. Third, we investigated the priming of defense gene expression conferred by bacterial VOCs as a means of eliciting plant ISR. Our results indicate that low concentrations of $B$. subtilis GB03 VOCs induce plant systemic resistance and defense responses, and protect Arabidopsis against infection by the necrotrophic pathogen $B$. cinerea. This study broadens the understanding of plant defense mediated by bacterial volatile compounds.

\section{MATERIALS AND METHODS}

\section{Evaluating Bacterial Volatile Effects on Botrytis cinerea Growth and Plant Protection from Infection}

To study the effects of $B$. subtilis GB03 VOCs on B. cinerea spore germination, we placed a small Petri dish measuring $40 \mathrm{~mm}$ diameter and $10 \mathrm{~mm}$ depth inside a larger Petri dish measuring $90 \mathrm{~mm}$ diameter and $15 \mathrm{~mm}$ depth. Tryptic soy broth (Difco Co, MD, USA) agar (TSA) medium was poured into the larger plate and allowed to solidify. Then, $0-3$ sterile filter paper disks (5 $\mathrm{mm}$ diameter) were placed around the periphery of the TSA 
plate. The disks were saturated with a $30 \mu \mathrm{l}$ suspension of $10^{8}$ colony forming units $(\mathrm{CFU}) / \mathrm{ml}$ of $B$. subtilis $\mathrm{GB} 03$. The inoculated plates were sealed with lids and incubated at $30^{\circ} \mathrm{C}$ for $24 \mathrm{~h}$. Then, $4 \mathrm{ml}$ of $1 \times 10^{5} \mathrm{CFU} / \mathrm{ml}$ of $B$. cinerea spores in half-strength potato dextrose broth (Difco Co, MD, USA) were added to the small $4 \mathrm{~cm}$ plate in the center of the inoculated $9 \mathrm{~cm}$ plate. The lid of the larger Petri dish was sealed with Parafilm and incubated at $25^{\circ} \mathrm{C}$ (Figure 2B). Spore germination was assessed after $6 \mathrm{~h}$ by observing 50 spores per replicate plate at $200 \times$ magnification (Nikon Eclipse E600, Osaka, Japan), and percentage germination was recorded. Spores with germinated mycelia longer than half of the spore diameter were considered as germinated.

The effect of bacterial VOCs on $B$. cinerea mycelial growth was investigated using the double-plate assay of Ting et al. (2011). A 9 cm dish containing TSA medium was prepared, 13 sterile filter paper disks $(5 \mathrm{~mm})$ were placed on the medium, and $30 \mu \mathrm{l}$ of $10^{8} \mathrm{CFU} / \mathrm{ml}$ of $B$. subtilis GB03 suspension was pipetted onto the filter disks. The plates were sealed with lids and incubated at $30^{\circ} \mathrm{C}$ for $24 \mathrm{~h}$. Then, agar plugs of $B$. cinerea mycelia were taken from the periphery of a plate containing a young growing culture, and the plugs were inserted into the center of a $9 \mathrm{~cm}$ Petri dish containing $20 \mathrm{ml}$ of PDA. This plate was inverted and securely fitted over the B. subtilis plate. The two plates were sealed together with Parafilm and incubated at $25^{\circ} \mathrm{C}$ (Figure 2A). Radial growth of the fungus was evaluated after 7 days.

The effect of bacterial VOCs on $B$. cinerea sporulation was examined using the same double-plate assay used for the mycelial growth test with slight modification. To evaluate sporulation, a plate was prepared with agar plugs of $B$. cinerea mycelia and incubated at $25^{\circ} \mathrm{C}$ until vegetative mycelial growth filled the plate. Then, this plate was inverted over the top of a TSA plate containing 1-3 sterile filter paper disks saturated with $30 \mu \mathrm{l}$ of B. subtilis GB03 suspension, the plates were sealed together using Parafilm, and incubated at $25^{\circ} \mathrm{C}$ for 7 days. Fungal spores were harvested with $10 \mathrm{mM} \mathrm{MgCl}_{2}$, and the spore suspensions were passed through gauze cloth to remove mycelial fragments. The numbers of spores produced under each bacterial VOC dosage were counted using a hemocytometer and a compound light microscope.

\section{Analysis of Mycelial Attachment to Polystyrene Surface}

The mycelial surface attachment evaluated in broth medium same as the method used to evaluate fungal spore germination. The layer of mycelium in top of broth medium showing the airmedium interface was photographed after 7 days (Figure 4). The surface attachment which reflects hydrophobic surface tendency, was evaluated using the crystal violet (CV) staining method according to Mowat et al. (2007). Briefly, the $4 \mathrm{~cm}$ Petri dishes (SPL, Pocheon-si, Gyeonggi-do, South Korea) containing fungi were washed four times with tap water to remove nonattached mycelia and spores. Petri dishes were air dried and attached mycelia were stained with $4 \mathrm{ml}$ of $0.5 \% \mathrm{CV}$ for $15 \mathrm{~min}$ at room temperature. Excess CV stain was removed by washing several times and gently pipetting off the rinsate until excess stain was removed. The remaining CV stain was solubilized by the addition of $4 \mathrm{ml}$ of $95 \%$ ethanol. Solubilized $\mathrm{CV}$ was gently pipetted off, and the absorbance at $\mathrm{OD}_{600}$ was determined using a spectrophotometer (Ultraspec 7000, Biochrom Co, Cambridge, England). Mycelia attachment to leaf surface have been assessed by microscopic inspection of Arabidopsis leaves after staining with Trypan blue according to (Koch and Slusarenko, 1990).

\section{Assessment of ISR in Plants Treated with Bacterial Volatiles}

Arabidopsis seeds were surface sterilized with $1 \%$ (v/v) sodium hypochlorite for $20 \mathrm{~min}$, rinsed three times in sterile distilled water (SDW), and placed on Petri dishes containing half-strength Murashige and Skoog (MS) medium (Duchefa Biochemie, Haarlem, The Netherlands) containing $0.8 \%(\mathrm{w} / \mathrm{v})$ plant agar and $1.5 \%(\mathrm{w} / \mathrm{v})$ sucrose $(\mathrm{pH} 5.8)$. The plates were placed in a growth cabinet with a $16 \mathrm{~h}$ light $/ 8 \mathrm{~h}$ dark cycle provided by fluorescent lights $(8,000 \mathrm{lux})$, and temperature was maintained at $22^{\circ} \mathrm{C}$ with $50-60 \%$ relative humidity. Two days after vernalization, seedlings were transferred to specialized plastic Petri dishes that contained a center partition (designated as I-plates). One chamber of the I-plate contained half-strength MS agar medium and the other chamber contained TSA onto which $5 \mathrm{~mm}$ diameter sterile filter paper disks had been placed. The seedlings were transferred to the chamber containing MS agar medium. The chamber containing TSA was inoculated with $30 \mu \mathrm{l}$ of a $B$. subtilis suspension or SDW applied dropwise onto the filter paper disk. Plates were sealed with Parafilm and transferred to the growth chamber using the same conditions. Fourteen days later, $5 \mu l$ of $B$. cinerea spore suspensions $\left(10^{5} \mathrm{CFU} / \mathrm{ml}\right)$ were drop-inoculated onto five leaves per Arabidopsis seedling. Leaves exhibiting symptoms were determined by visual inspection 3 days after inoculation.

\section{Differentiating Direct and Indirect Mechanisms of Bacterial VOC-Mediated Plant Protection from Botrytis cinerea Infection}

These experiments were performed using the I-plate method described by Ryu et al. (2004). Two-day-old Arabidopsis seedlings were transplanted into one chamber of an I-plate containing MS agar medium, and $30 \mu \mathrm{l}$ of $10^{8} \mathrm{CFU} / \mathrm{ml}$ B. subtilis GB03 suspension or distilled water control was pipetted onto a sterile filter paper disk on TSA medium in the other chamber. After 14 days of seedling exposure to VOCs, the plates were separated into two groups. In one group, the TSA medium and disks containing bacteria were removed from the I-plate (designated as the B. subtilis-removed group). In the other group, the TSA medium and disks containing bacteria was allowed to remain in the I-plate (designated as the B. subtilis-treated group). Subsequently, all plates were subjected to inoculation with $5 \mu \mathrm{l}$ of $B$. cinerea spore suspensions $\left(10^{5} \mathrm{CFU} / \mathrm{ml}\right)$ onto five leaves per Arabidopsis seedling. Disease severity was evaluated 3 days after pathogen challenge. 
Percentage of direct and ISR effect of VOCs on disease suppression calculated based on below formula:

Direct effect $=$

DS in B. subtilis removed - DS in B. subtilis treated DS in control - DS in B. subtilis treated

$$
\text { ISR }=\frac{\text { DS in control }- \text { DS in B. subtilis removed }}{\text { DS in control }- \text { DS in B. subtilis treated }} \times 100
$$

Where DS is disease severity percent.

\section{Evaluation of Plant Defense Priming using Quantitative RT-PCR}

Total RNA was isolated from inoculated 14-day-old leaf tissues $0,12,24$, and $36 \mathrm{~h}$ after $B$. cinerea inoculation according to the protocol of Yang et al. (2009). Total RNA was treated with $1 \mathrm{U}$ of RNase-free DNase (Promega, USA) for $10 \mathrm{~min}$ at $37^{\circ} \mathrm{C}$, and then subjected to a second round of purification using TRI reagent. First-strand cDNA synthesis was performed in $20 \mu \mathrm{l}$ of AccuPower RT PreMix (Bioneer, Korea) containing $1 \mu \mathrm{g}$ of DNase-treated total RNA, oligo(dT) primers, and Moloney murine leukemia virus reverse transcriptase (MMLV- RT; Invitrogen, USA). PCR reactions were performed according to the manufacturer's instructions. The candidate gene was analyzed using the following primers: 5'-GCTTCA GACTACTGTGAACC-3' (ChiB_F) and $5^{\prime}$-TCCACCGTTAATG ATGTTCG-3' (ChiB_R); $5^{\prime}$-AATGAGCTCTCATGGCTAAGTT TGCTTCC-3' ${ }^{\prime}\left(P D F 1.2 \_F\right)$ and $5^{\prime}$-AATCCATGGAATACACAC GATTTAGCACC-3' (PDF1.2_R); 5'-TTCCACAACCAGGCAC GAGGAG- $3^{\prime}\left(P R 1 \_F\right)$ and $5^{\prime}$-CCAGACAAGTCACCGCTACC C-3' (PR1_R). The AGI codes were as follows: CHIB (AT3G 12500), PDF1.2 (AT5G44420), PR1 (AT2G14610), and AtACT2 (AT3G18780). The control for equal loading was AtActin using the primers $5^{\prime}$-GTTAGCAACTGGGATGATATGG-3' and $5^{\prime}$ CAGCACCAATCGTGATGACTTGCCC-3'. Candidate priming genes were PCR-amplified from $100 \mathrm{ng}$ of cDNA using an annealing temperature of $60^{\circ} \mathrm{C}$. Amplified PCR products were separated by $2 \%$ agarose gel electrophoresis. The qRT-PCR assays were performed using a Chromo4 Real-Time PCR system (BioRad). Reaction mixtures $(10 \mu \mathrm{l})$ contained $5 \mu \mathrm{l}$ of $2 \times$ Brilliant SYBR Green qPCR master mix (Bio-Rad), cDNA, and $10 \mathrm{pM}$ of each primer. Thermocycle parameters were as follows: initial polymerase activation for $10 \mathrm{~min}$ at $95^{\circ} \mathrm{C}$, and then 40 cycles of $30 \mathrm{~s}$ at $95^{\circ} \mathrm{C}, 30 \mathrm{~s}$ at $60^{\circ} \mathrm{C}$, and $42 \mathrm{~s}$ at $72^{\circ} \mathrm{C}$. Conditions were determined by comparing the threshold values in a dilution series of the RT product, followed by a non-RT template control and a non-template control for each primer pair. Relative RNA levels were calibrated and normalized to the level of AtAct 2 mRNA.

\section{Statistical Analysis}

Data were subjected to analysis of variance (ANOVA) using JMP software (SAS Institute Inc., Cary, NC, USA). Significance of B. subtilis GB03 VOC treatment effects were determined by the magnitude of the $F$ value at $P=0.05$. When a significant $F$ value was obtained for treatments, separation of means was accomplished using Fisher's protected least significant difference (LSD) at $P=0.05$. Experiments done in four replicate and each experiment repeated for three time. The results of repeated trials of each experiment were similar. Therefore, one representative trial of each experiment is reported in the section "Results."

\section{RESULTS}

\section{Assessment of Bacterial VOC-Mediated Plant Protection Against B. cinerea Infection}

We tested the effects of bacterial VOCs on different stages of $B$. cinerea growth, including spore germination, mycelial growth, and spore production. First, we confirmed that pretreatment of plants with bacterial VOCs conferred protection against subsequent $B$. cinerea infection (Figure 1). A few leaves pretreated with $B$. subtilis GB03 VOCs developed very mild scars at the fungal inoculation site, whereas control leaves developed severe necrosis (Figure 1). Bacterial VOCs suppressed fungal growth and development at all phenological stages in a dose-dependent manner (Figures 2A-C). In all of these tests, inoculation of one filter paper disk with bacteria, which represented a low dose of VOCs, did not significantly affect mycelial growth, spore germination, and spore production (Figures 2A-C). Exposing B. cinerea to VOCs from two inoculated disks did not significantly affect mycelial growth and spore germination (Figures $2 \mathrm{~A}, \mathrm{C}$ ), but reduced spore production by $0.271 \log \mathrm{CFU} / \mathrm{ml}$ (Figure 2B). Exposing fungi to VOCs from three inoculated disks reduced mycelial growth, spore germination, and spore production by 61,64 , and $7 \%$, respectively (Figure 2). When the bacteria colonized the entire Petri dish, fungal growth was completely inhibited (data not shown).

\section{Differentiation of Direct versus Indirect Mechanisms of Plant Protection against Pathogen Infection by Bacterial VOCs}

We designed experiments to differentiate between direct inhibition of fungal growth by VOCs and indirect inhibition by VOC induction of plant systemic resistance. For these experiments, we used one filter disk inoculated with B. subtilis GB03. Arabidopsis seedlings were transplanted into one chamber of an I-plate and the other chamber contained TSA medium with one disk inoculated with $B$. subtilis GB03 or control disk with $30 \mu \mathrm{l}$ of distilled water. Plates were incubated in a growth chamber for 14 days. The plates containing GB03 were separated into two groups. In the first group, the TSA medium and disk containing bacteria were removed immediately before pathogen challenge. These plates no longer contained bacterial VOCs, and were designated as the "B. subtilis-removed" group (Figure 3A). In this group, only plant ISR could function against pathogen infection because there were no longer any VOCs to confer direct plant protection against $B$. cinerea colonization. In the second group, the bacteria were not removed (designated as "B. subtilis-treated"); therefore, there was continuous production 


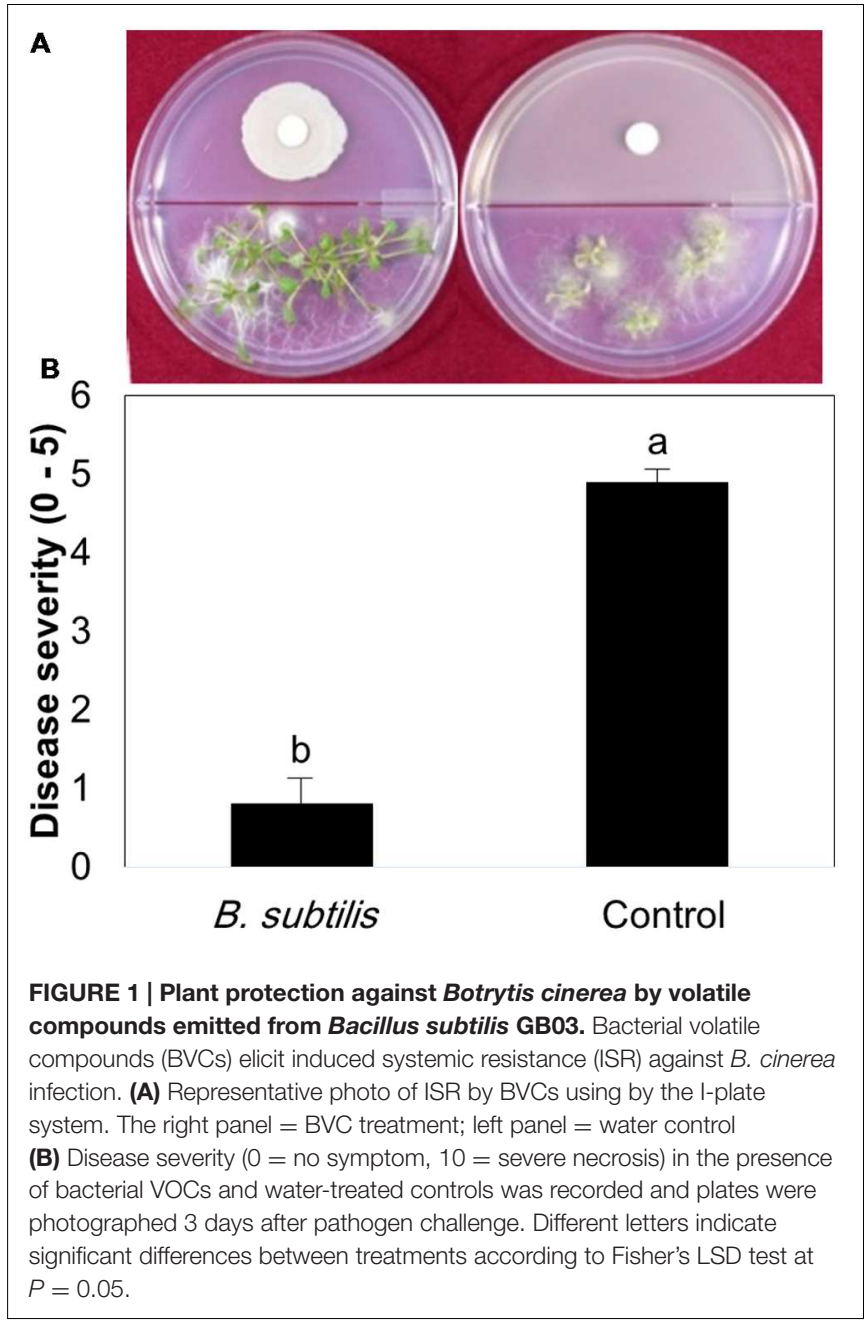

of volatiles, which could induce indirect fungal inhibition by eliciting plant ISR and direct antagonism (Figure 3A). Based on M\&M formula, ISR proportion was $90.63 \%$ and direct inhibition of fungi was $9.36 \%$ which mean that ISR have main role in suppression of $B$. cinerea on Arabidopsis in low concentration of VOCs (Figure 3B). Monitoring in vivo growth of $B$. cinerea on Arabidopsis by quantitative measurement of $\beta$-tubulin expression revealed that fungal growth inhibition was primarily due to stimulation of plant defense responses. There were differences between $\beta$-tubulin expressions in the "B. subtilis-removed" and "B. subtilis-treated" groups within $10 \mathrm{~h}$ post-infection (hpi). However, these effects were temporally unstable and were not significantly different at 20 and 30 hpi. There were no differences in $\beta$-tubulin expression levels between the "B. subtilis-removed" and "B. subtilis-treated" groups in 20 and 30 hpi.

\section{Effects of Bacterial VOCs on artificial Surface and Leaf Attachment of B. cinerea}

We performed microscopic investigation of $B$. cinerea colonization of Arabidopsis leaves. The results revealed that

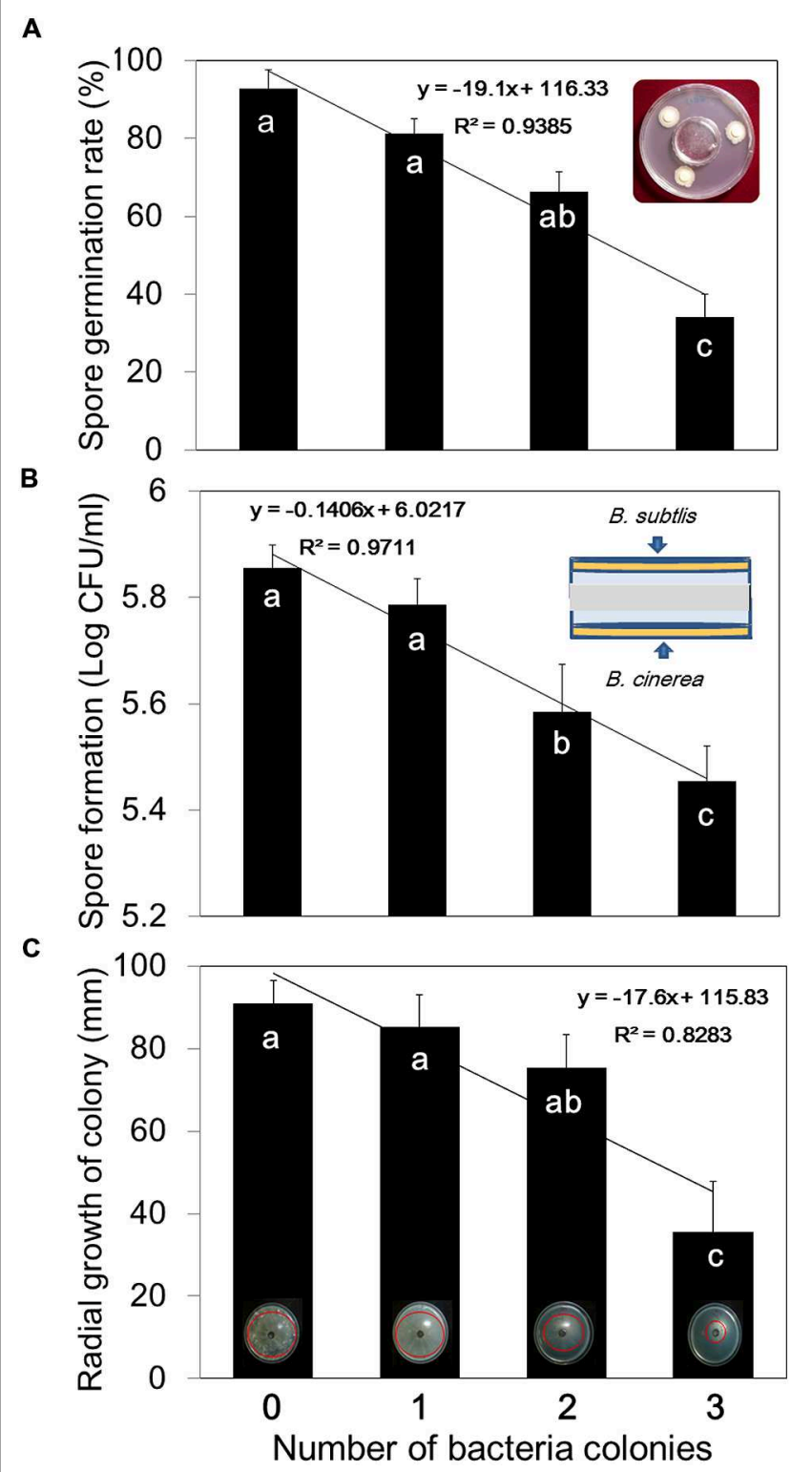

FIGURE 2 | Dose-dependent inhibition of $B$. cinerea mycelial growth, spore germination, and spore development by B. subtilis GB03 volatile compounds. (A) Spore germination, (B) spore formation, and (C) mycelial growth of $B$. cinerea were measured after 7 days in the presence of one, two, or three spot-inoculated filter disks ( $5 \mathrm{~mm}$ diameter) of $B$. subtilis GB03 bacterial suspension $\left(10^{8} \mathrm{CFU} / \mathrm{ml}\right)$ that were allowed to grow for $24 \mathrm{~h}$ before addition of fungi. Different letters indicate significant differences between treatments according to Fisher's LSD test at $P=0.05$. Error bars indicate standard error of the mean (SEM).

the "B. subtilis-treated" group displayed more aggressive epiphytic growth on leaf surfaces than that of the " $B$. subtilisremoved" group (Figure 3B). These experiments were performed using one filter disk inoculated with $B$. subtilis GB03; however, one inoculated disk did not significantly affect spore germination and mycelial growth. We concluded that VOCs might interfere in mycelial attachment to the leaf surface, and this could cause 
A

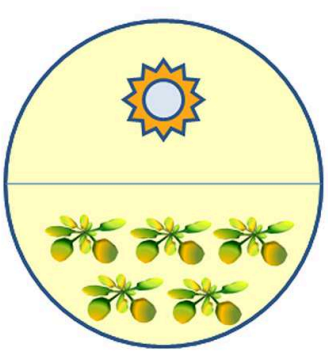

B. subtilis
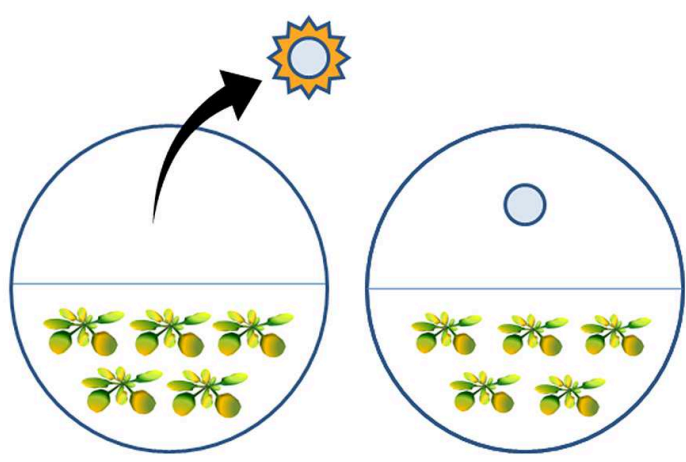

Removed B. subtilis

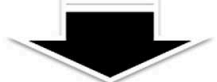

\section{B. cinerea challenge at day 14}

B

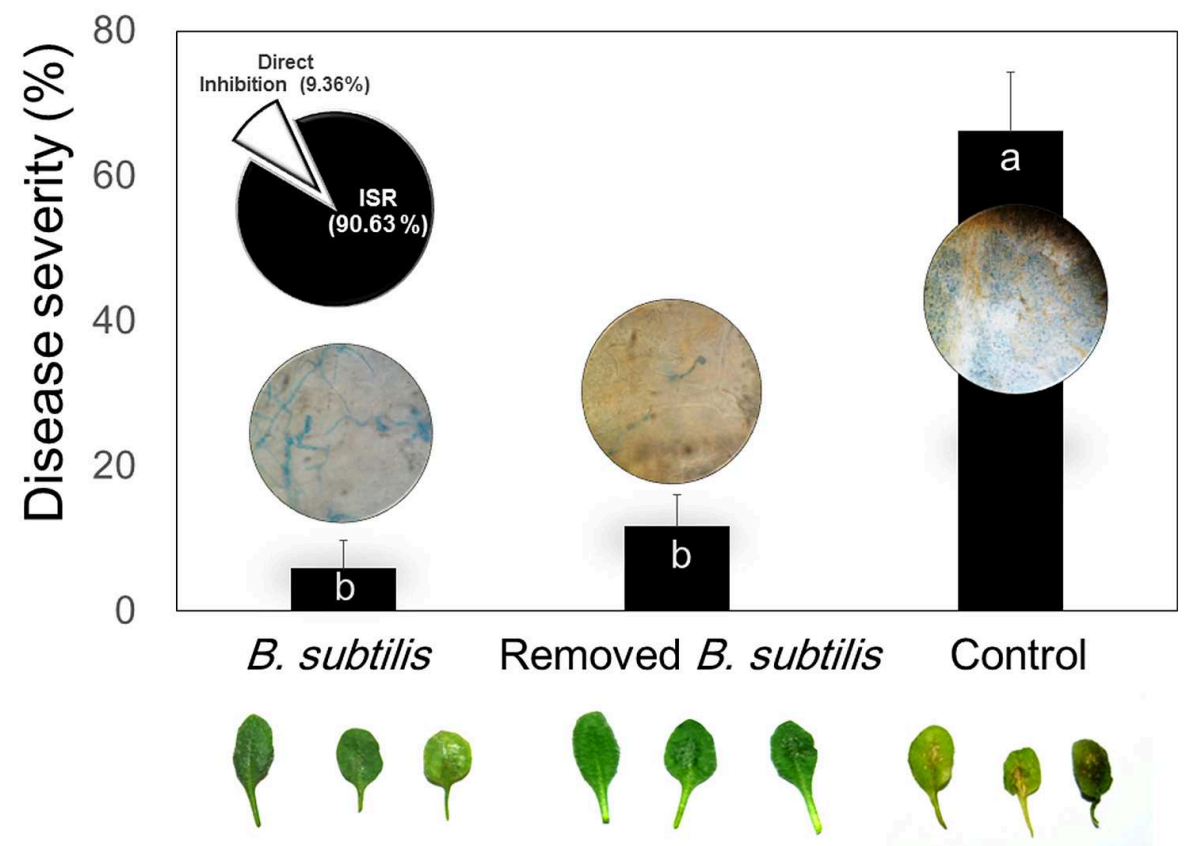

FIGURE 3 | Direct and indirect mechanisms of B. subtilis GB03 volatile compound effects on Botrytis cinerea and ISR of Arabidopsis. (A) Schematic of experimental design to test bacterial VOC-elicited ISR using the two-chamber I-plate system. Arabidopsis seedlings were grown in one chamber and B. subtilis GB03 were grown in the other chamber. The two chambers share the same head space, which allows bacterial volatiles to be transmitted to seedlings and inoculated fungal pathogens. In one group of plates, B. subtilis GB03 were removed before fungal inoculation at 14 days (middle image); in the other group, bacteria and volatile emission were retained (left image). Water-treated filter disks were used as control. (B) Disease severity caused by B. cinerea inoculation on Arabidopsis seedlings pretreated with $B$. subtilis GB03 VOCs, and in the presence and absence of continuing B. subtilis VOC emission. The inset pie graph indicates percentage plant protection conferred by VOC-elicited ISR (indirect mechanism) and by VOC-induced inhibition of fungal growth (direct mechanism). The inset photos above or inside bar graph indicate that $B$. subtilis GB03 volatile compounds inhibit leaf attachment of $B$. cinerea. Fungi growth were checked after staining with Trypan blue. Different letters indicate significant differences between treatments according to Fisher's LSD test at $P=0.05$.

epiphytic mycelial growth and inability to penetrate and colonize host tissue. We investigated mycelial surface attachment in the presence of bacterial VOCs using a universal biofilm formation method (Mowat et al., 2007). The results showed that VOCs emitted from one disk inoculated with GB03 were sufficient to reduce mycelial attachment to the hydrophobic Petri dish surface by $51 \%$. In the presence of VOCs emitted from three inoculated disks, mycelial surface attachment was reduced 


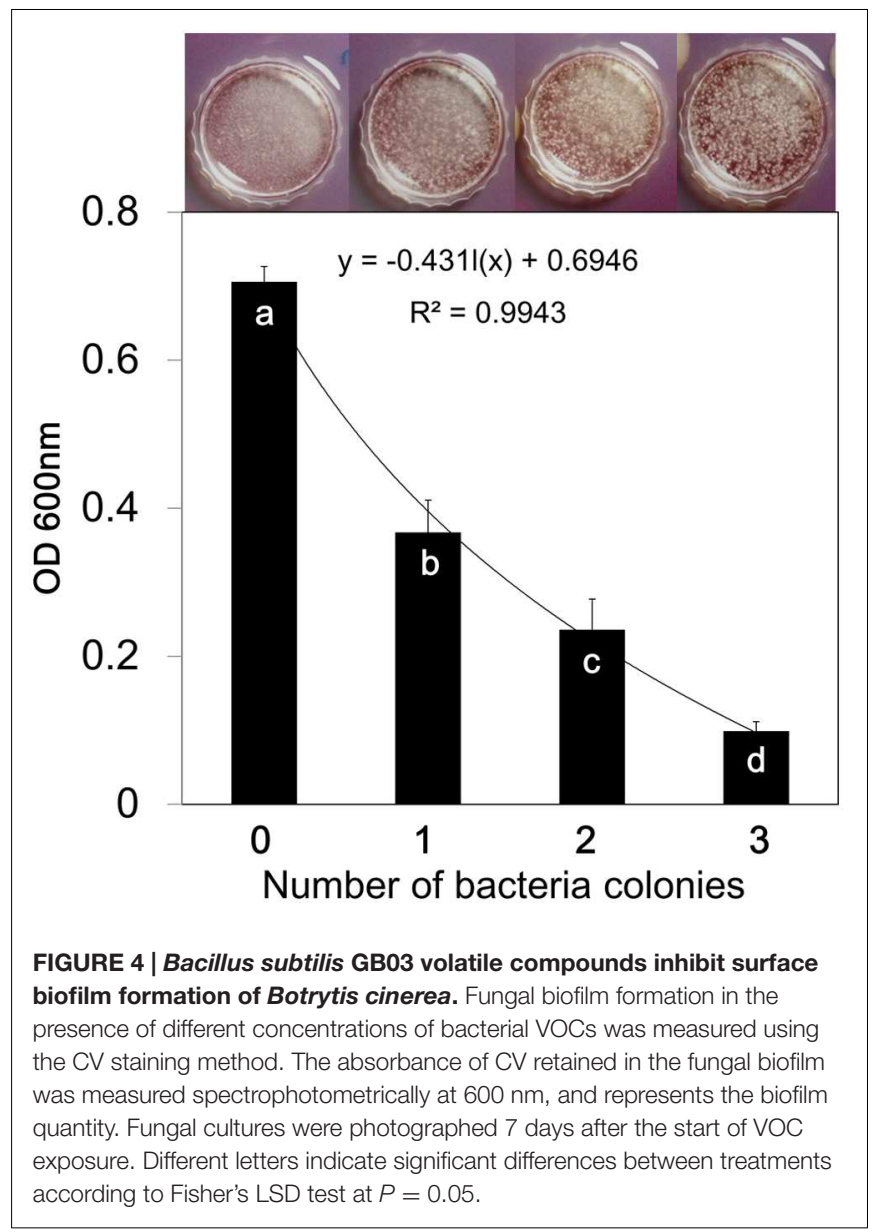

by sevenfold compared with that of the control (Figure 4). However, Higher VOC levels increased the air-liquid interface biofilm which means that fungi colonized surface of liquid media (Figure 4). A possible explanation for this aerotactic response could be an increase in mycelial hydrophilicity. Talbot et al. (1996) reported that production of cutinase and SC3 hydrophobin increased mycelial hydrophilicity. Therefore, it was possible that VOCs reduced mycelial attachment to the hydrophobic cuticular surface of the leaf. Further work is needed to confirm VOC effects on surface attachment regulation in B. cinerea. Our observations support the hypothesis that VOCs increase epiphytic growth of B. cinerea on Arabidopsis leaves. Although low VOC concentrations do not significantly affect fungal growth, they can affect some virulence factors such as host penetration (Figure 3).

\section{Bacterial VOC-Mediated Priming of Plant Defense Against B. cinerea Infection}

Volatile organic compounds-mediated plant defense priming was investigated using qRT-PCR analysis. The results indicate that JA signaling has a key role in VOC-elicited plant defense responses, because PDF1.2 expression was much higher in VOC-treated plants than in control plants. Maximum increases in PDF1.2 expression levels in VOC-treated and control plants were 13 and 4.6-fold, respectively, at $36 \mathrm{hpi}$ (Figure 5B). PR-1 expression, which is a marker of SA signaling, had a maximum 2.8-fold increase in VOC-treated plants at 12 hpi (Figure 5A). The activation of PDF1.2 and $P R-1$ at 36 and $12 \mathrm{hpi}$, respectively, represents early stages of disease establishment and plant defense priming. CHIB expression, which is a marker ET signaling, did not display statistically significant differences in VOC-treated and control plants (Figure 5C). This result is not in agreement with our previous results (Ryu et al., 2004), and other ET-dependent marker genes should be analyzed. Previous studies report that a necrotrophic pathogen activated the JA signaling pathway and suppressed SA-dependent pathways (Pieterse and Van Loon, 2007), and activation of one pathway (JA or SA) had antagonistic effects on the other (Pieterse et al., 2009). However, the present study indicates that GB03 VOCs activate both pathways.

\section{DISCUSSION}

The debate on direct and indirect effects of bacterial VOCmediated plant protection against pathogens arises because bacterial volatile compounds can directly inhibit pathogen growth (Chaurasia et al., 2005; Vespermann et al., 2007; Chen et al., 2008; Yuan et al., 2012) and indirectly elicit plant immune responses against target pathogens (Lee et al., 2012; Song and Ryu, 2013; Choi et al., 2014). Studies on direct effects of volatile compounds generally utilize very high volatile concentrations, which do not occur under natural conditions. Pedigo (1999) mentioned that high concentrations of any chemical can induce toxic effects. Studies on indirect effects of volatile compounds utilized low VOC concentrations by exposing plants and pathogens to one filter paper disks $(5 \mathrm{~mm}$ diameter) with confluent PGPR growth (Ryu et al., 2004; Lee et al., 2012). In present study, one filter disk did not significantly affect mycelial growth, spore germination, and spore production, but reduced disease severity by $60.26 \%$ (Figures 1 and 2). This indicates that VOC-elicited plant ISR is involved in plant protection when VOC concentrations are low. Park et al. (2015) shown that one colony of bacteria was enough to increase plant growth up to $80 \%$ in natural condition. They revealed that $5 \mathrm{ng}$ of 2-butanone is enough for promote plant growth. However, three filter paper disks significantly reduced mycelial growth, spore production, and spore germination (Figure 2). Exposing fungi to whole Petri dishes with confluently growing B. subtilis GB03 abolished mycelial growth. These results indicate that high VOC concentrations could be toxic for fungi. By contrast, treatment with low VOC concentrations (Ryu et al., 2004) or low levels of individual volatiles such as $0.2 \mathrm{pg}$ of 2,3 butanediol (Ryu et al., 2004), $10 \mu \mathrm{M}$ of MeJA (Jiang et al., 2015; Wang et al., 2015), 1 ppm of 2,4-Di-tert-butylphenol (Sang and Kim, 2012), 0.001 ppm of acetoin (Ann et al., 2013) or $100 \mu \mathrm{M}$ hexadecane (Park et al., 2013) reveal the indirect mechanism of VOC-elicited plant ISR. In our previous work, we showed that $100 \mu \mathrm{M}$ of pure volatiles acetoin, 2,3 butanediol, 3-pentanol and 1-pentanol had no negative effect on growth of 


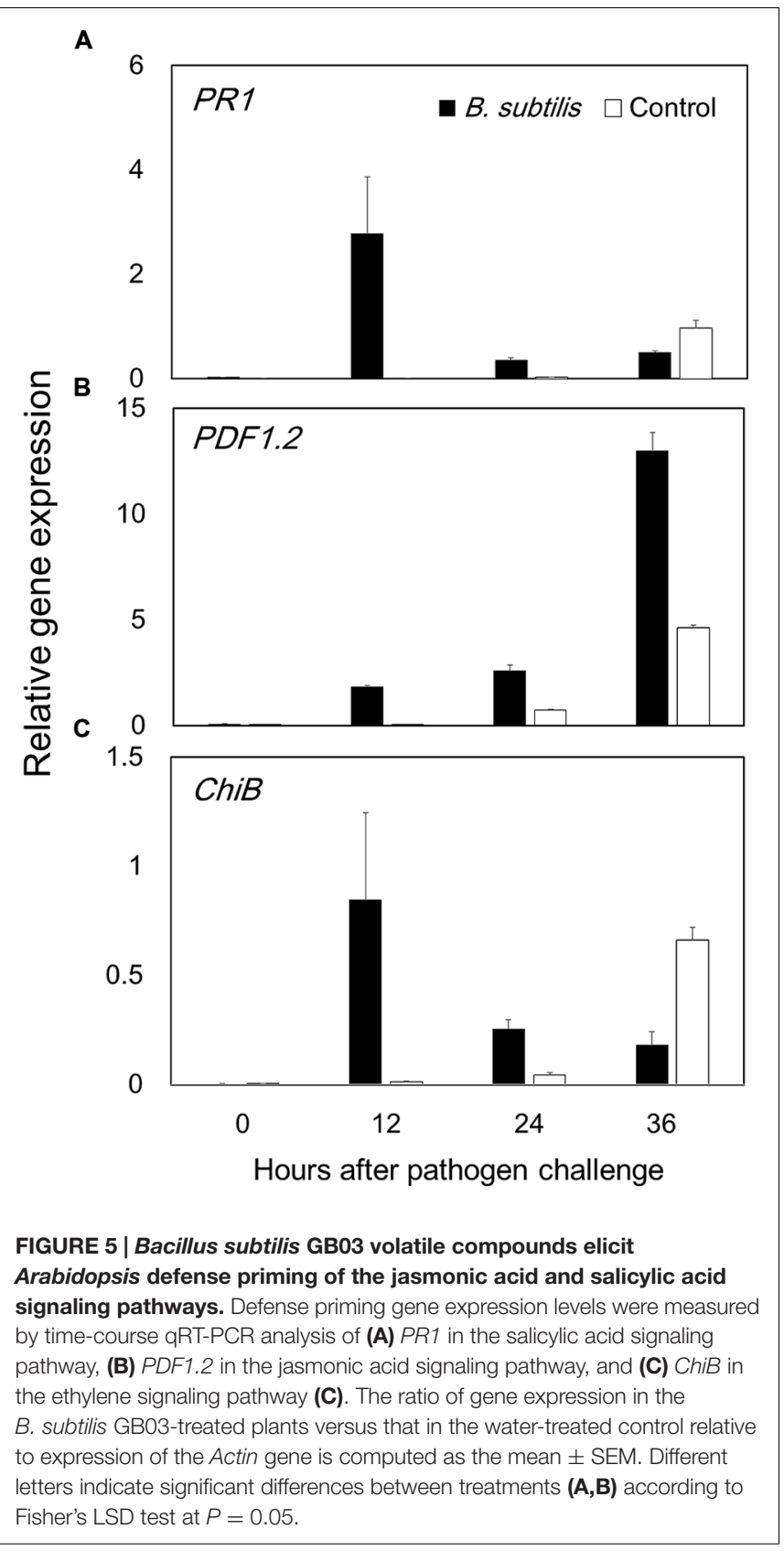

B. cinerea but suppressed disease on Arabidopsis (Sharifi et al., 2013).

The current study showed that VOC-elicited plant defense responses continued to be active after the bacteria and their emitted volatiles were removed, and plant immunity to infection was still observed at the time of pathogen challenge (Figure 3B). We suggests that direct VOC inhibition of fungal growth is only responsible for a small percentage $(9.36 \%)$ of the total VOC effect in suppressing $B$. cinerea. Microscopic inspection showed that volatiles have effect on surface attachment of $B$. cinerea. In the presence of VOCs emitted from one inoculated filter disks, fungi growth more epiphytic (Figure 3). However, expression of $\beta$-tubulin showed that there were difference in colonization between B. subtilis and removed B. subtilis just in $10 \mathrm{~h}$. There was no difference in leaf colonization in the presence or absence of VOCs at 20 and 30 hpi. Bacterial VOCs emitted from one filter disk were sufficient to reduce $B$. cinerea attachment to the leaf surface (Figure 4). This could suppress fungal penetration and induce epiphytic growth on the leaf surface (Talbot et al., 1996; Tucker and Talbot, 2001). Biotrophic and necrotrophic fungi need to tightly attach to the host cuticular surface and then penetrate the host tissue. Attachment to the host surface during the initial stage of fungal pathogenesis is crucial for fungal establishment on the host (Talbot et al., 1996; Tucker and Talbot, 2001; Harding et al., 2009). Altering the surface attachment efficiency of $B$. cinerea reduced or inhibited its pathogenicity (Doss et al., 1995; Epstein and Nicholson, 1997). QuintanaRodriguez et al. (2015) shown that volatiles emitted from diseased plant could increase resistance in neighbor susceptible plants. These volatiles also were able to directly inhibited conidia germination in vivo and in vitro but in dose dependent manner.

We evaluated VOC-elicited plant defense priming by performing a time-course qRT-PCR analysis of defense marker gene expression (Figure 5). We analyzed the expression of $P D F 1.2, P R-1$, and ChiB, which are involved in JA, SA, and ET signaling pathways, respectively. The highest gene expression achieved in PDF1.2 after B. subtilis GB03 treatment.PDF1.2 expression reached maximum at $36 \mathrm{hpi}$, which is within the typical plant defense priming temporal window. The JA signaling pathway is the primary pathway induced by necrotrophic fungi such as B. cinerea (Glazebrook, 2005). Our previous work revealed that Me-JA could suppress $B$. cinerea disease on Arabidopsis up to 40\% (Sharifi et al., 2013). PR-1 expression also displayed evidence of defense priming, with maximum expression occurring at $12 \mathrm{hpi}$. The present study observed that B. subtilis GB03 VOCs activated both JA and SA signaling pathways. Several studies report that Bacillus strains can simultaneously activate JA and SA pathways, and SA, JA, and ET pathways (Buensanteai et al., 2009; Rudrappa et al., 2010; Niu et al., 2011; Lee et al., 2012; Choi et al., 2014). The B. subtilis volatile compound acetoin activated expression of both $P R-1$ and PDF1.2 (Rudrappa et al., 2010). Tridecane from Paenibacillus polymyxa E681 induced PR-1 and VSP2 expression (Lee et al., 2012).

\section{CONCLUSION}

We intended to link information from two types of reports. Researcher who mentioned that, volatiles are responsible for direct fungi growth inhibition and researchers who report that, ISR is mechanism of volatiles action. The optimum VOCs concentration that did not inhibit the fungus in vitro still elicit plant defense strategies to prevent subsequent Botrytis infection (Figures 2 and 4). Low VOCs concentrations elicit plant ISR, which is an indirect mechanism that results in $90.63 \%$ of disease suppression (Figure 3). By contrast, direct inhibition of fungal growth and development by low VOC concentrations accounts for $9.36 \%$ of the total disease suppression (Figure 3). The direct mechanism may become 
more prominent with higher VOC concentrations in a dosedependent manner. JA was the main signaling pathway in activation of plant defense by means of B. subtilis GB03 volatiles (Figure 5). However, there were no cross-talk between SA and JA signaling pathway as expression of both genes increased.

\section{AUTHOR CONTRIBUTIONS}

RS conceived and performed experiments, interpreted data and contributed to the drafting of the manuscript. CMR gave experimental advice, interpreted data, and contributed to the

\section{REFERENCES}

Agrios, G. N. (2004). Plant Pathology, 5th Edn. San Diego: Academic Press.

Ann, M. N., Cho, Y. E., Ryu, H. J., Kim, H. T., and Park, K. S. (2013). Growth promotion of tobacco plant by 3-hydroxy-2-butanone from Bacillus vallismortis EXTN-1. Korean J. Pesti. Sci. 17, 388-393. doi: 10.7585/kjps.2013.17. 4.388

Balmer, D., Planchamp, C., and Mauch-Mani, B. (2013). On the move: induced resistance in monocots. J. Exp. Bot. 64, 1249-1261. doi: 10.1093/jxb/ ers 248

Buensanteai, N., Yuen, G. Y., and Prathuangwong, S. (2009). Priming, signaling, and protein production associated with induced resistance by Bacillus amyloliquefaciens KPS46. World J. Microbiol. Biotechnol. 25, 1275-1286. doi: 10.1007/s11274-009-0014-6

Chaurasia, B., Pandey, A., Palni, L. M. S., Trivedi, P., Kumar, B., and Colvin, N. (2005). Diffusible and volatile compounds produced by an antagonistic Bacillus subtilis strain cause structural deformations in pathogenic fungi in vitro. Microbiol. Res. 160, 75-81. doi: 10.1016/j.micres.2004.09.013

Chen, H., Xiao, X., Wang, J., Wu, L., Zheng, Z., and Yu, Z. (2008). Antagonistic effects of volatiles generated by Bacillus subtilis on spore germination and hyphal growth of the plant pathogen. Botrytis. Cinerea. Biotechnol. Lett. 30, 919-923. doi: 10.1007/s10529-007-9626-9

Cho, S. M., Kang, B. R., Han, S. H., Anderson, A. J., Park, J. Y., Lee, Y. H., et al. (2008). 2R,3R-butanediol, a bacterial volatile produced by Pseudomonas chlororaphis O6, is involved in induction of systemic tolerance to drought in Arabidopsis thaliana. Mol. Plant Microbe Interact. 21, 1067-1075. doi: 10.1094/MPMI-21-8-1067

Choi, H. K., Song, G. C., Yi, H. S., and Ryu, C. M. (2014). Field evaluation of the bacterial volatile derivative 3-pentanol in priming for induced resistance in pepper. J. Chem. Ecol. 40, 882-892. doi: 10.1007/s10886-014-0488-Z

Cortes-Barco, A., Goodwin, P., and Hsiang, T. (2010a). Comparison of induced resistance activated by benzothiadiazole, $(2 \mathrm{R}, 3 \mathrm{R})$-butanediol and an isoparaffin mixture against anthracnose of Nicotiana benthamiana. Plant Pathol. 59, 643653. doi: $10.1111 / j .1365-3059.2010 .02283 . x$

Cortes-Barco, A., Hsiang, T., and Goodwin, P. (2010b). Induced systemic resistance against three foliar diseases of Agrostis stolonifera by $(2 \mathrm{R}, 3 \mathrm{R})$-butanediol or an isoparaffin mixture. Ann. Appl. Biol. 157, 179-189. doi: 10.1111/j.17447348.2010.00417.x

Doss, R. P., Potter, S. W., Soeldner, A. H., Christian, J. K., and Fukunaga, L. E. (1995). Adhesion of germlings of Botrytis cinerea. Appl. Environ. Microbiol. 61, 260-265.

Epstein, L., and Nicholson, R. N. (1997). "Adhesion of spores and hyphae to plant surfaces," in The Mycota. V. Plant Relationships, eds G. C. Carroll and P. Tudzynski (Berlin: Springer-Verlag), 11-25.

Farag, M. A., Ryu, C.-M., Sumner, L. W., and Paré, P. W. (2006). GC-MS SPME profiling of rhizobacterial volatiles reveals prospective inducers of growth promotion and induced systemic resistance in plants. Phytochemistry 67, 22622268. doi: 10.1016/j.phytochem.2006.07.021

Farag, M. A., Zhang, H., and Ryu, C.-M. (2103). Dynamic chemical communication between plants and bacteria through airborne signals: induced resistance by drafting of the manuscript. All authors contributed to the discussion and approved the final manuscript.

\section{ACKNOWLEDGMENTS}

This work was supported by the Industrial Source Technology Development Program of the Ministry of Knowledge Economy (10044909) of Korea, the BioNano Health-Guard Research Center funded by the Ministry of Science (ICT), the Future Planning of Korea as a Global Frontier Project (Grant H-GUARD_2013M3A6B2078953), and the KRIBB Research Initiative Program, Republic of Korea.

bacterial volatiles. J. Chem. Ecol. 39, 1007-1018. doi: 10.1007/s10886-0130317-9

Fiddaman, D. J., and Rossall, S. (1993). The production of antifungal volatiles by Bacillus subtilis. J. Appl. Bacteriol. 74, 119-126. doi: 10.1111/j.13652672.1993.tb03004.x

Glazebrook, J. (2005). Contrasting mechanisms of defense against biotrophic and necrotrophic pathogens. Annu. Rev. Phytopathol. 43, 205-227. doi: 10.1146/annurev.phyto.43.040204.135923

Han, S. H., Lee, S. J., Moon, J. H., Park, K. H., Yang, K. Y., Cho, B. H., et al. (2006). GacS-dependent production of 2R, 3R-butanediol by Pseudomonas chlororaphis $\mathrm{O} 6$ is a major determinant for eliciting systemic resistance against Erwinia carotovora but not against Pseudomonas syringae pv. tabaci in tobacco. Mol. Plant Microbe Interact. 19, 924-930. doi: 10.1094/MPMI-19-0924

Harding, M. W., Marques, L. L. R., Howard, R. J., and Olson, M. E. (2009). Can filamentous fungi form biofilms? Trends Microbiol. 17, 475-480. doi: 10.1016/j.tim.2009.08.007

Hartmann, A., and Schikora, A. (2012). Quorum sensing of bacteria and transkingdom interactions of $\mathrm{N}$-acyl homoserine lactones with eukaryotes. J. Chem. Ecol. 38, 704-713. doi: 10.1007/s10886-012-0141-7

Jiang, L., Jin, P., Wang, L., Yu, X., Wang, H., and Zheng, Y. (2015). Methyl jasmonate primes defense responses against Botrytis cinerea and reduces disease development in harvested table grapes. Sci. Horticult. 192, 218-223. doi: 10.1016/j.scienta.2015.06.015

Kai, M., Effmert, U., Berg, G., and Piechulla, B. (2007). Volatiles of bacterial antagonists inhibit mycelial growth of the plant pathogen Rhizoctonia solani. Arch. Microbiol. 187, 351-360. doi: 10.1007/s00203-0060199-0

Kanchiswamy, C. N., Malnoy, M., and Maffei, M. E. (2015a). Chemical diversity of microbial volatiles and their potential for plant growth and productivity. Front Plant Sci. 13:151. doi: 10.3389/fpls.2015.00151

Kanchiswamy, C. N., Malnoy, M., and Maffei, M. E. (2015b). Bioprospecting bacterial and fungal volatiles for sustainable agriculture. Trends Plant Sci. 20, 206-211. doi: 10.1016/j.tplants.2015.01.004

Kishimoto, K., Matsui, K., Ozawa, R., and Takabayashi, J. (2007). Volatile 1-octen3-ol induces a defensive response in Arabidopsis thaliana. J. Gen. Plant Pathol. 73, 35-37. doi: 10.1007/s10327-006-0314-8

Kloepper, J. W., Ryu, C.-M., and Zhang, S. (2004). Induced systemic resistance and promotion of plant growth by Bacillus spp. Phytopathology 94, 1259-1266. doi: 10.1094/PHYTO.2004.94.11.1259

Koch, E., and Slusarenko, A. (1990). Arabidopsis is susceptible to infection by a downy mildew fungus. Plant Cell 2, 437-445. doi: 10.1105/tpc.2.5.437

Lee, B., Farag, M. A., Park, H. B., Kloepper, J. W., Lee, S. H., and Ryu, C. M. (2012). Induced resistance by a long-chain bacterial volatile: elicitation of plant systemic defense by a C13 volatile produced by Paenibacillus polymyxa. PLoS ONE 7:e48744. doi: 10.1371/journal.pone.0048744

Lee, S. M., Chung, J., and Ryu, C.-M. (2015). Augmenting plant immune responses and biological control by microbial determinants. Res. Plant Dis. 21, 161-179.

Lyon, G. (2007). "Agents that can elicit induced resistance," in Induced Resistance for Plant Defense: A Sustainable Approach to Crop Protection, eds D. Walters, A. Newton, and G. Lyon (Oxford: Wiley-Blackwell), 9-29. 
McCain, A. H. (1966). A volatile antibiotic produced by Streptomyces griseus. Phytopathology 56, 150.

Mowat, E., Butcher, J., Lang, S., Williams, C., and Ramage, G. (2007). Development of a simple model for studying the effects of antifungal agents on multicellular communities of Aspergillus fumigatus. J. Med. Microbiol. 56, 1205-1212. doi: 10.1099/jmm.0.47247-0

Mysore, K. S., and Ryu, C. M. (2004). Nonhost resistance: how much do we know? Trends Plant Sci. 9, 97-104. doi: 10.1016/j.tplants.2003.12.005

Niu, D.-D., Liu, H.-X., Jiang, C.-H., Wang, Y.-P., Wang, Q.-Y., Jin, H.-L., et al. (2011). The plant growth-promoting rhizobacterium Bacillus cereus AR156 induces systemic resistance in Arabidopsis thaliana by simultaneously activating salicylate- and jasmonate/ethylene-dependent signaling pathways. Mol. Plant Microbe Interact. 24, 533-542. doi: 10.1094/MPMI-09-10-0213

Park, H. B., Lee, B., Kloepper, J. W., and Ryu, C. M. (2013). One shot-two pathogens blocked: exposure of Arabidopsis to hexadecane, a long chain volatile organic compound, confers induced resistance against both Pectobacterium carotovorum and Pseudomonas syringae. Plant Signal Behav. 8:e24619. doi: $10.4161 /$ psb.24619

Park, Y.-S., Dutta, S., Ann, M., Raaijmakers, J. M., and Park, K. (2015). Promotion of plant growth by Pseudomonas fluorescens strain SS101 via novel volatile organic compounds. Biochem. Biophys. Res. Commun. 461, 361-365. doi: 10.1016/j.bbrc.2015.04.039

Pedigo, L. P. (1999). Entomology and Pest Management, 3rd Edn. (New Jersey, NJ: Prentice Hall), 691.

Pieterse, C. M., Leon-Reyes, A., Van der Ent, S., and Van Wees, S. C. (2009). Networking by small-molecule hormones in plant immunity. Nat. Chem. Biol. 5, 308-316. doi: 10.1038/nchembio.164

Pieterse, C. M. J., and Van Loon, L. C. (2007). "Signaling cascades involved in induced resistance," in Induced Resistance for Plant Disease Control: A Sustainable Approach to Crop Protection, eds D. Walters, A. Newton, and G. Lyon (Oxford: Blackwell Publishing), 65-88.

Quintana-Rodriguez, E., Morales-Vargas, A. T., Molina-Torres, J., Ádame-Alvarez, R. M., Acosta-Gallegos, J. A., and Heil, M. (2015). Plant volatiles cause direct, induced and associational resistance in common bean to the fungal pathogen Colletotrichum lindemuthianum. J. Ecol. 103, 250-260. doi: 10.1111/13652745.12340

Rudrappa, T., Biedrzycki, M. L., Kunjeti, S. G., Donofrio, N. M., Czymmek, K. J., Paré, P. W., et al. (2010). The rhizobacterial elicitor acetoin induces systemic resistance in Arabidopsis thaliana. Commun. Integr. Biol. 3, 130-138. doi: 10.4161/cib.3.2.10584

Ryals, J. A., Neuenschwander, U. H., Willits, M. G., Molina, A., Steiner, H.-Y., and Hunt, M. D. (1996). Systemic acquired resistance. Plant Cell 8:1809. doi: $10.2307 / 3870231$

Ryu, C. M., Farag, M. A., Hu, C. H., Reddy, M. S., Wei, H. X., Kloepper, J. W., et al. (2004). Bacterial volatiles induce systemic resistance in Arabidopsis. Plant Physiol. 134, 1017-1026. doi: 10.1104/pp.103.026583
Sang, M. K., and Kim, K. D. (2012). The volatile-producing Flavobacterium johnsoniae strain GSE09 shows biocontrol activity against Phytophthora capsici in pepper. J. Appl. Microbiol. 113, 383-398. doi: 10.1111/j.13652672.2012.05330.x

Sharifi, R., Ahmadzade, M., Behboudi, K., and Ryu, C. M. (2013). Role of Bacillus subtilis volatiles in induction of systemic resistance in Arabidopsis. Iranian J. Plant Prot. Sci. 44, 91-101.

Song, G. C., and Ryu, C. M. (2013). Two volatile organic compounds trigger plant self-defense against a bacterial pathogen and a sucking insect in cucumber under open field conditions. Int. J. Mol. Sci. 14, 9803-9819.

Talbot, N. J., Kershaw, M. J., Wakley, G. E., de Vries, O. M. H., Wessels, J. G. H., and Hamer, J. E. (1996). MPG1 encodes a fungal hydrophobin involved in surface interactions during infection-related development of Magnaporthe grisea. Plant Cell 8, 985-999. doi: 10.2307/3870210

Ting, A. S. Y., Mah, S. W., and Tee, C. S. (2011). Detection of potential volatile inhibitory compounds produced by endobacteria with biocontrol properties towards Fusarium oxysporum f. sp. cubense race 4. World J. Microbiol. Biotechnol. 27, 229-235. doi: 10.1007/s11274-010-0447-y

Tucker, S. L., and Talbot, N. J. (2001). Surface attachment and pre-penetration stage development by plant pathogenic fungi. Annu. Rev. Phytopathol. 39, 385-417. doi: 10.1146/annurev.phyto.39.1.385

Vespermann, A., Kai, M., and Piechulla, B. (2007). Rhizobacterial volatiles affect the growth of fungi and Arabidopsis thaliana. Appl. Environ. Microbiol. 73, 5639-5641. doi: 10.1128/AEM.01078-07

Wang, K., Liao, Y., Kan, J., Han, L., and Zheng, Y. (2015). Response of direct or priming defense against Botrytis cinerea to methyl jasmonate treatment at different concentrations in grape berries. Int. J. Food Microbiol. 194, 32-39. doi: 10.1016/j.ijfoodmicro.2014.11.006

Yang, J. W., Yu, S. H., and Ryu, C. M. (2009). Priming of defense-related genes confers root-colonizing bacilli-elicited induced systemic resistance in pepper. Plant Pathol. J. 25, 389-399. doi: 10.5423/PPJ.2009.25.4.389

Yuan, J., Raza, W., Shen, Q., and Huang, Q. (2012). Antifungal activity of Bacillus amyloliquefaciens NJN-6 volatile compounds against Fusarium oxysporum $\mathrm{f}$. sp. cubense. Appl. Environ. Microbiol. 78, 5942-5944. doi: 10.1128/AEM.01 $357-12$

Conflict of Interest Statement: The authors declare that the research was conducted in the absence of any commercial or financial relationships that could be construed as a potential conflict of interest.

Copyright $\odot 2016$ Sharifi and Ryu. This is an open-access article distributed under the terms of the Creative Commons Attribution License (CC BY). The use, distribution or reproduction in other forums is permitted, provided the original author(s) or licensor are credited and that the original publication in this journal is cited, in accordance with accepted academic practice. No use, distribution or reproduction is permitted which does not comply with these terms. 